\title{
The eight essential elements of inclusive STEM high schools
}

\author{
Melanie LaForce ${ }^{1 *}$, Elizabeth Noble ${ }^{1}$, Heather King ${ }^{1}$, Jeanne Century ${ }^{1}$, Courtney Blackwell ${ }^{1}$, Sandra Holt², \\ Ahmed Ibrahim ${ }^{1}$ and Stephanie Loo
}

\begin{abstract}
Background: Inclusive STEM (traditionally known to stand for "Science, Technology, Engineering, and Math") high schools are emerging across the country as a mechanism for improving STEM education and getting more and diverse students into STEM majors and careers. However, there is no consensus on what these schools are or should be, making it difficult to both evaluate their effectiveness and scale successful models. We addressed this problem by working with inclusive STEM high school leaders and stakeholders to articulate and understand their intended school models. This "bottom-up" approach is in contrast with other studies that have taken a "top-down," literature-based approach to defining STEM schools.

Results: Through this process, we identified 76 critical components of STEM schools and derived a theoretical framework of eight elements that represent the common goals and strategies employed by inclusive STEM high schools across the country: Personalization of Learning; Problem-Based Learning; Rigorous Learning; Career, Technology, and Life Skills; School Community and Belonging; External Community; Staff Foundations; and External Factors. This framework offers a clear picture of what exactly inclusive STEM schools are and common language for both researchers and practitioners. Interestingly, STEM disciplinary content did not emerge as a defining component across school models.
\end{abstract}

Conclusions: Findings suggest that STEM school leaders and stakeholders view their STEM school identity as rooted in pedagogy, transferrable skills, school culture, and rigorous instruction across all subjects, including, but not restricted to, STEM. This raises questions about the goals of inclusive STEM high schools and the STEM discipline outcomes that we should reasonably expect to see from STEM schools.

Keywords: STEM education, STEM schools, Conceptual framework

\section{Background}

The STEM education movement has gained dramatic momentum over the past decade. This is reflected not only in the proliferation of local and state STEM programs that now exist across the country, both in schools and out, but also in the numerous federal reports and policies, the federal budget, and initiatives like the White House's Educate to Innovate (National Research Council (NRC) 2011, 2013; National Academies 2005; President's Council of Advisors in Science and Technology (PCAST) 2010). During his administration, President Obama has made improving STEM education a priority, backed by a

\footnotetext{
*Correspondence: laforce@uchicago.edu

1 Outlier Research \& Evaluation, UChicago STEM Education, University of

Chicago, 1427 E. 60th Street, Chicago, IL 60637, USA

Full list of author information is available at the end of the article
}

5-year strategic plan to support STEM education, released in 2013. This attention to STEM education is due in large part to the need to bolster the US STEM workforce to compete in a global economy (United States Department of Labor, 2007). According to predictions, the number of jobs in the STEM sector will increase more rapidly over the next decade than jobs in any other sector (Committee on STEM Education National Science and Technology Council 2013; Klobuchar, 2014): analysts estimate that by 2018, non-STEM jobs will increase by $9.8 \%$, while STEM jobs will increase by $17 \%$ (Langdon et al. 2011). Coming on top of an already-existing shortage of qualified STEM workers, these projections seem cause for serious concern.

Some have characterized this shortage as the result of a "leaky pipeline" (Alper 1993; Leboy 2008; Valla \& Ceci 2014) through which students, especially women and 
other underrepresented groups, leave STEM fields. The metaphor suggests that somewhere in the course of their preK-16 education, these groups either lose interest in STEM-related learning, lose confidence in their abilities to perform in these fields (Wells, Sanchez, \& Attridge 2007; Unfried, Faber, \& Wiebe 2014), or feel that the "STEM culture" is not welcoming to them (Good, Rattan, \& Dweck 2012; Smith, Lewis, Hawthorne, \& Hodges 2013), resulting in large numbers of students opting out of (or not opting into) STEM majors and careers (e.g., Blickenstaff 2006; Wickware 1997). Thus, many efforts to improve STEM education seek to grow student interest and achievement through increased time and emphasis on STEM subjects, different approaches to the content, and the use of a variety of instructional strategies. One such strategy is the creation of inclusive STEM high schools, which aim to provide rigorous STEM learning (Riley et al. 2013) to students of all socio-economic, demographic, and achievement backgrounds (Peters-Burton et al. 2014).

Despite the attention and resources being given to STEM and STEM schools, there remains little consensus about what STEM schools should look like in practice and even about what "STEM" actually is in the operational context of K12 education. Some definitions of STEM focus on disciplinary integration. For example, Merrill (2009) defines STEM as

a standards-based, meta-discipline residing at the school level where all teachers, especially science, technology, engineering, and mathematics (STEM) teachers, teach an integrated approach to teaching and learning, where discipline-specific content is not divided, but addressed and treated as one dynamic, fluid study (pg. 1).

Others take the interdisciplinary nature one step further by proposing that efforts to integrate STEM subjects should expand to encompass the arts, thus shifting the "STEM" initiative to the "STEAM" initiative (Science, Technology, Engineering, Arts, and Mathematics; Platz 2007).

In contrast, still others see the STEM movement as an opportunity to highlight subject-specific content that had previously been overlooked. More specifically, they highlight the "T" or the "E" in STEM (e.g., "Staking the Claim for the 'T' in STEM" [Kelley, 2010], "Supporting the $\mathrm{T}$ and the E in STEM" [Harrison, 2011], "Advancing the "E" in K-12 STEM Education" (Rockland et al. 2010)).

Despite this lack of shared definition, there are numerous schools around the country that identify themselves-in name, mission, or otherwise-as STEM schools. Selective enrollment math- and science-focused high schools, which admit based on achievement, have existed for several decades (e.g., Subotnik, Tai, \& Almarode 2011). These often highly competitive schools, however, serve only a small portion of the student population, and enrollment of minority students has typically been low (Means, Confrey, House, \& Bhanot 2008). Inclusive STEM high schools, which are the focus of the current study, have no admissions criteria for students and as such serve a broader and often more diverse population of students (Means et al. 2008; NRC 2011). These schools have more recently emerged as a trend and are now found around the country. Beyond the surface-level characteristic of their enrollment structure, however, the ways and extent to which inclusive STEM high schools are similar or different in their intended models and practice has been to largely unknown-which poses a problem for research on STEM schools as a singular innovation.

Researchers are already beginning to engage in comparative studies of inclusive STEM schools and their surrounding non-STEM counterparts (e.g. Young et al. 2011); however, what is lacking from the current body of literature on STEM schools is an examination of what STEM schools are in actuality-what they do, how they interpret the term "STEM," what their goals are-and thus what outcomes we can and should expect from them. Without shared language to describe STEM schools, findings about impact will not contribute to a developing knowledge base that can inform continued growth and improvement.

In this study, we address the questions: What is an inclusive STEM high school? What specific components are present in these schools? Why are components present, meaning, what specific outcomes are intended for students, staff, and the community at large? We examine how inclusive STEM high schools themselves articulate what they are; how this may (or may not) align with the national push for improved science, technology, engineering, and math education; and the outcomes they intend for their students. Understanding the intended models and specific model components of functioning inclusive STEM schools allows us to examine the implementation of strategies and how that implementation relates to outcomes, as well as to develop a comprehensive theoretical framework of common STEM school practices, which we present here. This framework can inform future research and suggest a widely applicable model that will provide policy-makers and practitioners with common ground for discussion and collaboration. It can also help interested practitioners understand, implement, and improve the practices these STEM schools use. The insight gained from this study about what STEM school leaders believe makes their schools "STEM schools" also illuminates the definition of STEM that these leaders are employing, which has important implications for understanding student STEM outcomes.

\section{Methods}

\section{Theoretical approach}

This paper describes the findings of the "STEM School Study" (S3; NSF \#1238552), which examined 20 inclusive 
STEM high schools across the USA. We sought to derive a theoretical model for inclusive STEM high schools by employing a "component approach," (Century et al. 2010; Hall \& Hord 1987) working to identify and clearly describe the critical components of each of the 20 inclusive STEM high school models, identify commonalities, and synthesize them into key conceptual elements. The component approach has roots in educational change literature where Hall and Hord (1987) suggested that to analyze different instantiations of an innovation (in this case, the inclusive STEM high school), "the components or building blocks of the innovation must be defined" (p. 117). This approach has become increasingly visible in educational implementation studies as an essential step toward understanding the parts of educational interventions that are most closely associated with desired student outcomes (Damschroder et al. 2009). Some refer to these critical components as "critical program dimensions," "model dimensions," "fidelity criteria," "essential characteristics," and "critical parts" (Bond et al. 2000; Huntley: Operationalizing the concept of "fidelity of implementation" for NSF-funded mathematics curricula, unpublished 2005; Mowbray et al. 2003; Sabelli \& Dede 2001; Wang et al. 1984). In S3, we identified what we refer to as "critical components" that in turn comprise larger conceptual "elements."

Our specific component framework is based in our previous work on measuring the fidelity of implementations (Century \& Cassata 2014), which was then adapted for specific study of STEM schools in a precursor study to S3 (the Ohio STEM Learning Network Study (OSLN; NSF \#1008569), which examined five inclusive STEM high schools in Ohio). The framework organizes innovation components into two broad categories: structural components and interactional components. Structural components "include the organizational, design, and support elements that are the building blocks of the innovation" (Century \& Cassata 2014, p. 88); interactional components are the expected or intended behaviors of the innovation's users-in this case, the participants in the school community.

It is important to stress that the strategy employed in this study (S3), as well as the previous OSLN study, used a qualitative, ground-up approach, in that it relied on the schools' creators, leaders, and key teachers to articulate their STEM school models. The eight element model that was ultimately derived is rooted in the school leaders' own descriptions. This approach stands in contrast to Peters-Burton et al. (2014), for example, who utilized a literature-driven approach wherein they identified 10 "critical components" of STEM schools in existing literature, and then conducted in-depth case studies of inclusive STEM schools to examine the extent to which these components were present. Our approach was driven by a commitment to ascertaining what STEM schools actually are, on the ground, as defined by their creators and leaders. Then, we sought to synthesize their descriptions into a general model of inclusive STEM high schools that would benefit the field as a whole.

\section{Sample}

Sample schools reside in seven states. This includes four schools each in Ohio, Texas, and Washington State; three in California; two each in North Carolina and Tennessee; and one in New York, for a total of 20. The research team worked closely with state-level STEM policy leaders to select and recruit participant schools that (1) were inclusive, in that they had no achievement-based admissions criteria; (2) were representative of the range of inclusive STEM schools across each state; and (3) had the capacity (staff, time, and administrator support) to participate in a large research study. The final criterion was necessary in order to (a) complete the research study and (b) not overburden school personnel or detract from their duties at their respective schools. We sought schools that were in at least their second year of implementation with two exceptions (new STEM schools in Ohio and Tennessee were included, as network leaders felt confident in their abilities to participate). We also required that schools selfidentified (as per the administration) as "STEM" schools (with "STEM" left open to their interpretation). All schools were affiliated with centralized state STEM networks, though their level of involvement varied. Of the 20 schools, seven were suburban, nine were urban, and four were rural. School sample size ranged from 44 to 619 students. Ethnic distribution of students varied: one school was majority African American/Black, seven were majority Hispanic/Latino, and 12 were majority white. The total student sample (as reported on questionnaires during the second year of the study) was 11.6\% African American/ Black; $0.6 \%$ American Indian or Alaska Native; $9.0 \%$ Asian; 28.6\% Hispanic/Latino; 1.3\% Hawaiian or Pacific Islander; 1.5\% Middle Eastern; 33.7\% White/Caucasian; $7.2 \%$ Mixed race; $1.9 \%$ other; and $4.6 \%$ preferred not to answer. As the final sample included a range of schools with varying demographics and from a large diversity of contexts (e.g., geographic, socio-economic, political), we are confident that findings from this study are generalizable to a broad range of STEM schools across the nation.

\section{Data collection strategy and sources}

Figure 1 demonstrates the data collection and analysis process for the study. Our data collection strategy was informed by Leithwood and Montgomery (1980), who suggest that researchers should derive information about the essential components of a program from (a) the program developers, (b) written materials produced by 


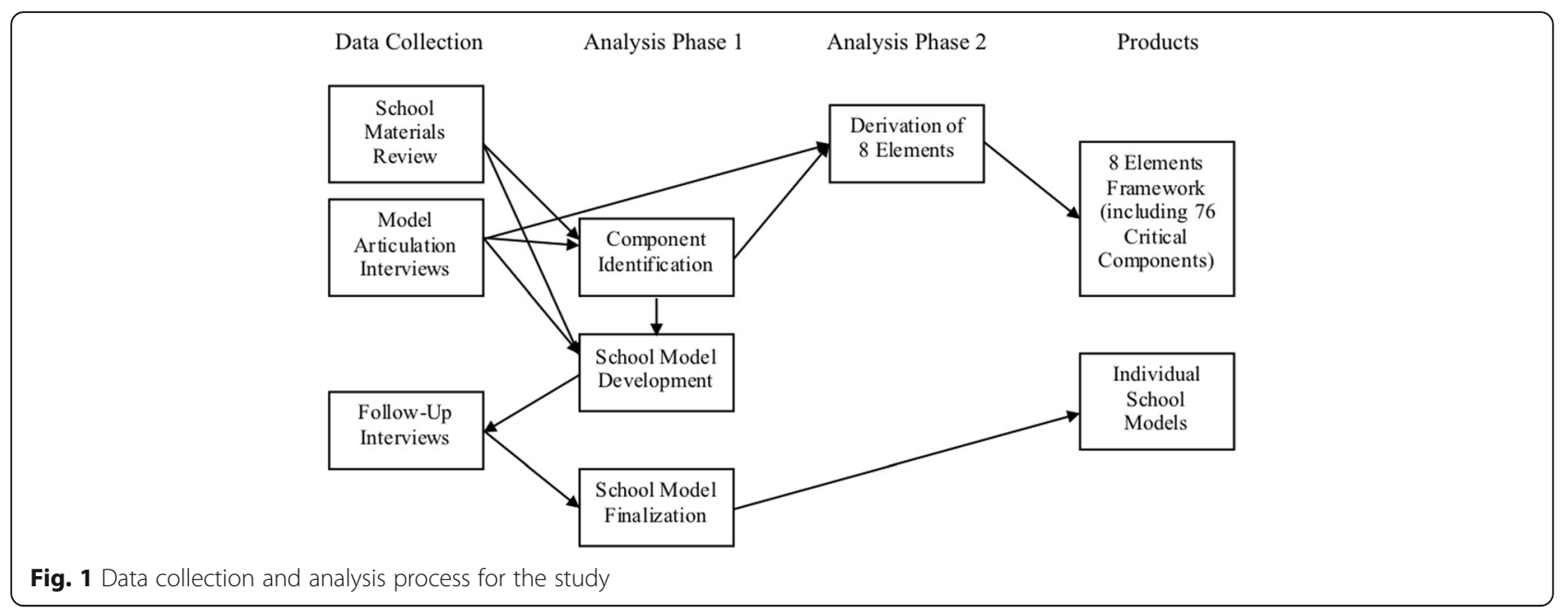

those developers, and (c) individuals involved in program implementation. Thus, we began the process of articulating each school's critical components by reviewing schools' written materials and conducting "model articulation" interviews with the school stakeholders who were most knowledgeable about each respective STEM school model (e.g., school founders, principals, and lead teachers).

We obtained written materials about each school from school leaders and school websites, including mission statements, student and parent handbooks, policy documents, presentation materials, links to news stories, school videos, and other descriptive documents. We reviewed these documents prior to the model articulation interviews in order to gain a basic understanding of each of the schools and provide context for the interviews themselves.

We conducted one model articulation interview with each school $(N=20)$; interviews included one to six leaders at each school (most interviews were conducted with two to three leaders). Participants included school founders, school leaders, key external partners (e.g., community advisors), and lead teachers. Eighteen took place during the spring of 2013, while the remaining two were conducted the following school year due to complications in scheduling. The model articulation interviews used a semi-structured interview process, with an interview protocol adapted from Gugiu and Rodriguez-Campos (2007) that focused on precisely delineating and identifying each school model's critical components. Each interview began with the question, "What are the most important elements or components of your school?" The protocol then directed interviewers to probe for more detail on the components so that each could be fully described and provided a number of sample questions and prompts for use as appropriate. In addition to asking the stakeholders to identify and describe the critical components of their school's model, these prompts were also used to elicit why the components were critical (i.e., the outcomes they were intended to produce), how they would describe the component to a new student or teacher, what they look like in practice, and which structures or supports may be present to ensure that the component is enacted as intended. For example, if advisory was mentioned as a core component of a school, interviewers followed up by asking questions such as, "Can you define what you mean by advisory? What are you trying to accomplish for students or for the school by having an advisory class? If I were a new student, how would you describe advisory to me? What do you want teachers to know about advisory and why it is an important part of the school?" These probing questions were asked for each component mentioned by participants. We reiterated during these conversations that our focus was on the school's intentional model or what the school was trying to do or accomplish, rather than what might just be happening there. Each interview lasted up to $2 \mathrm{~h}$.

Follow-up interviews were conducted with 16 of the 20 schools during the 2013-2014 school year. (Two schools were no longer participants in the study at that point. At the other two schools, we were unable to arrange a time for these interviews with school leaders due to time constraints and scheduling issues despite multiple attempts; however, these schools continued participation in all other aspects of the study including teacher, student, and school leader questionnaires, and in one case, an on-site visit for qualitative data collection). In each follow-up interview, the school leader was present; at some, other stakeholders present during the initial model articulation interviews were present as well. These interviews lasted for approximately $1 \mathrm{~h}$ each; the first half of the interview centered on the drafted individual school model, while the second half focused on gaining deeper understanding of two particular critical components (problem-solving projects and partner- 
supported instruction) in each school that identified these as important pieces of their models.

\section{Data analysis phase 1-identifying the critical components of inclusive STEM high schools}

A second (non-speaking) researcher took detailed notes during each model articulation interview, and each interview was subsequently transcribed verbatim using HyperTranscribe software. Researchers reviewed critical components identified from the five Ohio inclusive STEM high schools in the previously mentioned OSLN study. Then, one researcher conducted a comprehensive coding of each interview with a focus on identifying critical components. Researchers conducted the coding by annotating the interview transcripts in Microsoft Word using the comment function and then organized the coded critical components using Excel spreadsheets. After the first researcher completed coding, a second researcher, typically one who was present during the articulation interview, reviewed the codes. Both researchers then met to reconcile any differences.

\section{Verifying the components in each STEM school model}

In the next stage of the model articulation process, researchers organized the components into a graphic summary model for each school (see Fig. 2 for an example). We shared each STEM school's model with that school's stakeholders to gauge face validity, asking school staff about the accuracy and importance of the components identified in the model, and whether they felt any important part of their school was not represented. In general, school stakeholders felt that models were accurate representations of their school. Only a few suggested slight language changes or inclusion of another critical component. Researchers discussed any issues or concerns raised by school leaders or other participants and made agreedupon changes to the draft models. Each school's final model included 11-31 critical components agreed upon by two researchers and school interviewees. In total, we identified 76 distinct critical components across all of the schools (see Table 1 for a list of the components and the number of schools that consider each component core to its model).

Data analysis phase 2-deriving the essential elements from identified critical components

After identifying the 76 critical components present across all of the S3 schools, we used a grounded-theory approach (Strauss \& Corbin 1994) to explore whether we could derive an overarching theoretical framework for inclusive STEM schools in general, as we recognized that a comprehensive list of 76 different critical components was too detailed to provide a clear understanding of just what inclusive STEM high schools are. To derive this framework, we used a three-step process of (a) model articulation interview transcript review; (b) thematic coding of
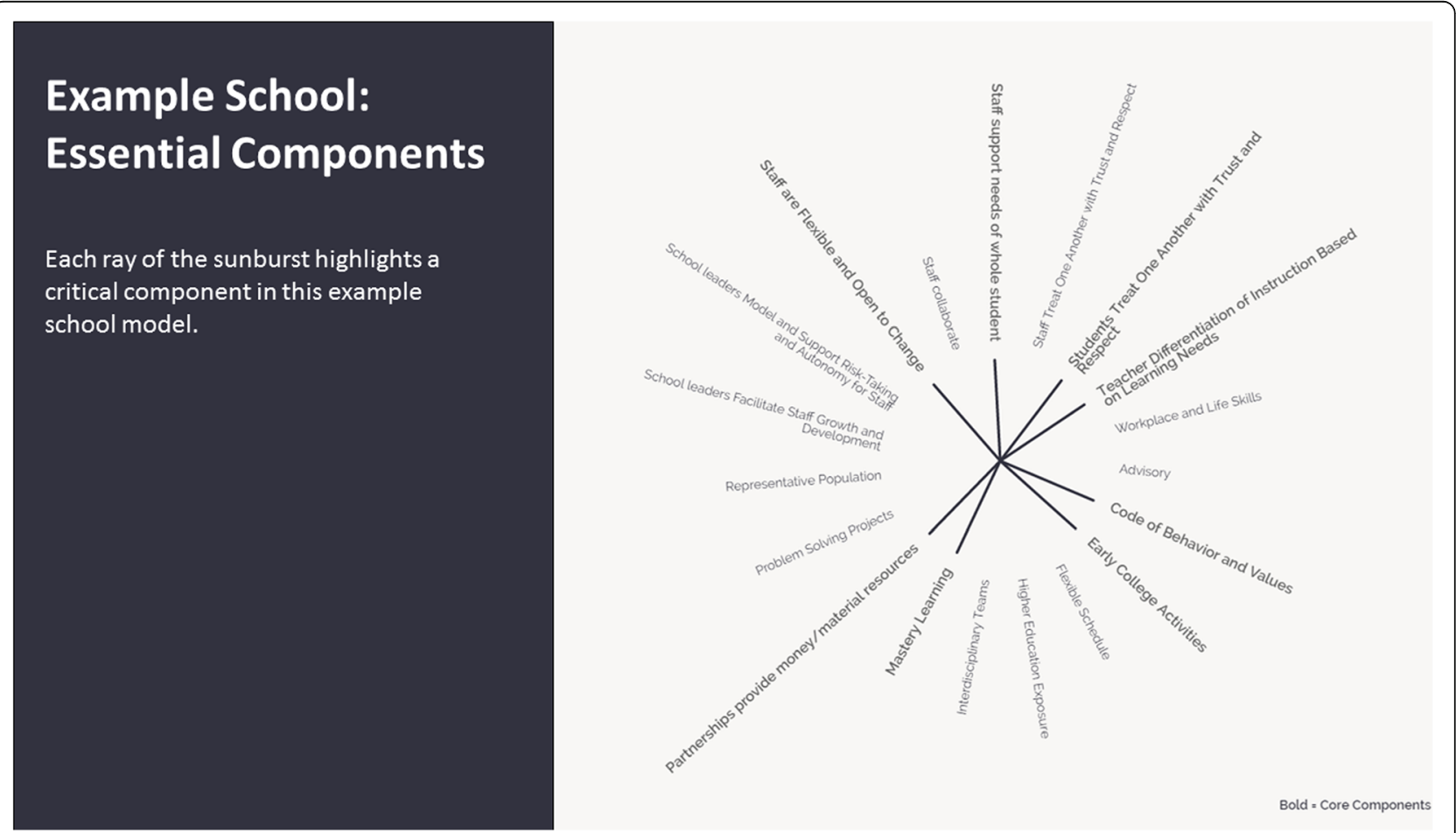

Fig. 2 Graphic summary model for each school 
Table 1 The 8 Elements and components

Problem-Based Learning - Core Instructional (20)

- Students make interdisciplinary connections (9)

- Students demonstrate autonomy (13)

- Students reflect on their learning (2)

- Interdisciplinary teams (5)

- Intersession (2)

- Problem-solving projects (17)

- Staff-created curriculum (9)

- Partners support instruction (17)

- Teacher facilitation of teamwork and collaboration among students (14)

- Teacher facilitation of students making interdisciplinary connections (9)

- Teacher facilitation of student interest (4)

- Teacher facilitation of students engaging in an engineering design process (5)

- Teacher facilitation of students engaging with real-world content (11)

- Students cooperate and work with one another as teams (14)

- Students make connections between the content they are learning,

the real world, and their lives (11)

- Teacher facilitation of student self-reflection (1)

- Teacher facilitation of student autonomy (13)

Rigorous Learning - Core Instructional (20)

- Teacher facilitation of students engaging with real-world content (11)

- Staff-created curriculum (9)

- Students engage in cognitively demanding work (6)

- Core course sequence (7)

- Mastery learning (6)

- Partners support instruction (17)

- Teacher facilitation of students making interdisciplinary connections (9)

- Teacher use of assessment to inform instruction (6)

- Students make interdisciplinary connections (9)

- Students participate in tutoring (2)

- Students participate in early college activities (11)

- Students make connections between the content they are learning, the real world, and their lives (11)

- Teacher facilitation of students doing cognitively demanding work (6)

Personalization of Learning - Core Instructional (20)

- Teacher differentiation of instruction based on learning needs (4)

- Teacher facilitation of student interest (4)

- Teacher use of assessment to inform instruction (6)

- Advisory (11)

- Small school and/or classes (5)

- Flexible schedule (11)

- Student access to school throughout the day (2)

- Teacher/partner facilitation of students engaging in career-readiness activities (13)

- Teacher facilitation of student autonomy (13)

- Staff supports needs of whole student (17)

- Students engage and participate in career readiness (13)

- Students demonstrate autonomy (13)

Career, Technology, and Life Skills - Core Instructional (20)

- Students participate in early college activities (11)

- Students use technology (11)

- Students use workplace and life skills (11)

- Instructional themes (5)

- Partners support instruction (17)

- Teacher facilitation of student autonomy (13)

- Teacher/partner facilitation of students engaging in career-readiness activities (13)

- Teacher facilitation of students learning skills specifically related to the workplace and life (11)

- Teacher facilitation of teamwork and collaboration among students (14)
(Career, Technology, and Life Skills cont.)

- Teacher models use of new and current technologies (11)

- Students cooperate and work with one another as teams (14)

- Students demonstrate autonomy (13)

- Students engage and participate in career readiness (13)

- Students engage and participate in service learning (8)

- Students participate in demonstrations of learning (11)

- Students participate in higher education exposure activities (10)

School Community and Belonging - Core Non-Instructional (19)

- Students treat each other with trust and respect (6)

- Extracurricular activities (7)

- Student induction process (4)

- Small school and/or classes (5)

- Student access to school throughout the day (2)

- Teacher facilitation of a positive social and emotional learning environment (6)

- Staff emphasizes code of behavior and values (9)

- Staff support needs of whole student (17)

- Students contribute to school decision-making (7)

- Students demonstrate code of behavior and values (9)

External Community - Core Non-Instructional (16)

- School establishes and maintains a community presence (5)

- Students participate in service learning (8)

- Staff spreads practices (2)

- Staff establishes and maintains partnerships (5)

- Partners facilitate spread of practices (3)

- Partners help establish and maintain community presence (2)

Staff Foundations Supporting (20)

- Staff collaborate (17)

- Staff reflect on work (5)

- School leaders facilitate staff growth and development (8)

- Common planning time (12)

- Individual planning time (2)

- Non-instructional staff (3)

- School leaders model instructional practice (1)

- School leaders model and support risk-taking and autonomy for staff (6)

- Staff engages in relevant professional development/growth activities (9)

- Staff has a sense of school ownership (3)

- Staff participates in decision-making (7)

- Staff treat one another with trust and respect (2)

- Staff works with autonomy (8)

- Stem instructional leaders support instruction (1)

Essential Factors Supporting (19)

- Staff are flexible and open to change (11)

- Representative population (10)

- Professional development resources (2)

- Family involvement (7)

- Online management system (3)

- Open physical space (1)

- Regional school (2)

- Partners provide money/material resources (5)

- Standards (8)

- Staff believe all students can learn (7)

The number in parentheses indicates the number of schools that consider each component core to its model and that have at least one component in that element, respectively 
the critical components; and (c) discussion. Researchers analyzed school stakeholder descriptions of why components are critical, as well as their descriptions of what the components should look like in practice. For example, when school stakeholders indicated that student autonomy was a critical component, we studied the interview transcript and context to understand what this looks like in the classroom. One school leader described how students make decisions in their classes about what content to research and how they will then share the information with other students. This autonomy strategy satisfies a school goal of personalizing instruction-a strategy that allowed students to work with their own interests and favorite presentation styles. By synthesizing school leaders' descriptions of the underlying educational goals for all components during the interviews, we derived eight themes that encompassed all 76 components, articulated as the eight essential elements of inclusive STEM high schools (see Table 1 for a complete list of the elements and components). We named the elements in ways that we thought were clear, broadly understandable, and, when possible, already defined in the literature; that is, while the components and elements were derived from what the schools themselves said, the element names were assigned by the research team.

\section{Results}

The eight elements include six core elements (four instructional and two non-instructional) as well as two supporting elements. Instructional elements focus on pedagogical strategies and achieving academic goals for students. Noninstructional elements are comprised of strategies that do not directly focus on the academic advancement of students. These non-instructional elements represent schools' intentions to facilitate student social and emotional outcomes, as well as to improve the greater STEM education system (beyond the school itself). Supporting elements include strategies and external factors that support both Instructional and non-instructional elements. Each of the eight elements is described in more detail below.

It is worth noting that some components appear in more than one element. For example, the component "Teacher Facilitation of Students Engaging in RealWorld Content" is part of the "Rigorous Learning" Element as well as the "Problem-Based Learning" Element. This is because the use of real-world content is both a higher-order thinking strategy (and thus, is part of more rigorous learning (Brundiers et al. 2010)), as well as a key part of the pedagogy underlying problem-based learning. Components may be present in more than one element because the goals and strategies of teaching and learning are complex, and we decided not to artificially isolate them under one element. This flexibility in the framework allows for a more comprehensive understanding of the purpose and function of each individual component. Not every school included each element in its model (see Table 1), and even when elements were present, each school emphasized different components to differing degrees, defining their unique school models.

\section{The eight essential elements Instructional elements}

Personalization of Learning The Personalization of Learning Element represents the idea that learning should be customized for each student's unique ability and interests. The Bill and Melinda Gates Foundation (2014) defines personalized learning as "[s]ystems and approaches that deepen student learning by tailoring instruction to each individual student's needs, skills, and interests" (p. 2). Personalization of Learning takes the classroom away from a "one-size-fits-all" strategy to allow for truly individualized instruction. Examples of components that comprise the Personalization of Learning Element include "teacher differentiation of instruction based on learning needs," "flexible schedule," and "student autonomy."

Problem-Based Learning (PBL) Generally speaking, PBL is an instructional approach that requires students to solve a problem to meet a learning goal (Savery 2015). However, school leaders defined PBL in many ways. For example, PBL may involve a long-term project that takes place over several weeks or it may take place within one class period. Some PBL tasks or projects involve fabricated problems, while others focus on a problem that exists in the real world. However, the components within the PBL Element encompass strategies that PBL definitions share. Components that comprise the PBL Element include "students make interdisciplinary connections," "external partners support instruction," and "teacher facilitation of students engaging in real-world content."

Rigorous Learning Rigorous Learning refers to instruction that focuses on content and processes that are challenging for the students and call for high cognitive demand. Blackburn (2008) defines rigor in the classroom as "creating an environment in which the student is expected to learn at high levels, and each student is supported so he or she can learn at high levels, and each student demonstrates learning at high levels" (p. 2). Examples of components that comprise the Rigorous Learning Element include "teacher facilitation of students engaging in real-world content," "students engage in cognitively demanding work," and "core course sequence." 
Career, Technology, and Life Skills This element entails instruction and learning experiences that focus on proficiencies that students will use in college, future careers, and life in general. Components may focus specifically on the development of knowledge and skills necessary to join the STEM workforce, and/or include skills that will be useful in any future workplace, such as communication and time management. Examples of components included in this element include "students use technology," "students participate in career-readiness activities" (e.g., internships), and "student-led demonstrations of learning."

\section{Non-instructional elements}

School community and belonging This element focuses on non-instructional aspects of student development. This includes instilling a strong school culture and providing students with support for emotional needs. Many inclusive STEM high schools describe their culture as a crucial piece of student success. Some schools described a "family" culture, while others focused on a school-wide culture of professionalism, for example. Other examples of components that comprise this element include "staff support the needs of the whole student," "students treat each other with trust and respect," "students contribute to school decision-making," and "staff emphasize on a school code of behavior and values."

External Community External Community represents schools' efforts and commitment to establishing and maintaining relationships with community members and institutions. In some cases, schools may have a strong commitment to giving back to their local or state community. In others, schools may focus on their presence in the STEM education community and feel that a critical part of their success includes sharing best practices and strategies with other schools. Examples of components that comprise this element include "school establishes and maintains a community presence," "staff spread practices," and "students participate in service learning."

\section{Supporting elements}

Staff Foundations This element centers on intentional activities in a school's model that enable instructional and non-instructional teacher behaviors. Staff Foundations are components that "set the stage" for student-directed components to take place. In order to implement instructional and non-instructional components such as those described above, schools in our sample report that certain foundations must be in place. For example, "staff collaboration" and "school leader supports staff growth and development" can set the foundation for components such as "teacher facilitation of interdisciplinary connections" (found in the Problem-Based Learning and Rigorous Learning Elements) to occur. Other examples of components included in this element include "staff participate in decision-making" and "common planning time."

Essential Factors The model articulation process also yielded a group of factors (contexts and conditions) that school stakeholders identified as key to the successful implementation of their schools. We define factors as components external to the school model (i.e. not part of the school itself) that can contribute to or inhibit implementation (Century et al. 2012). Factors may include characteristics of the organization where the innovation resides, the external climate (political, community) surrounding the innovation, and characteristics of the user. For example, some schools described "family involvement" as an important support for enacting the school's mission. Other schools described key staff attitudes (such as a "belief that all students can learn") as a necessary support to reaching school goals. Both family involvement and staff attitudes, although not technically part of the inclusive STEM high schools themselves, can affect implementation of the school model. Several of these factors were of such importance to the schools that we felt they warranted inclusion as one of the eight elements in the framework. Other components in essential factors include "staff are flexible and open to change" and designation as a "regional school."

\section{Discussion}

The eight elements show that high-quality, constructivist practices are central to our STEM schools' models. The components described by school leaders as critical to their model represent a variety of pedagogical approaches, skills that students may use in future academic and career endeavors, and strategies for engaging staff, students, and communities.

It is important to make a note on the consensus of these components and elements across our school sample. The goal of determining the components of STEM schools was not to identify "What are things that all STEM schools do?" nor to dictate what STEM schools should do. Rather, it was to ask, "What are all the things that STEM schools do?" and to create shared language within which STEM schools (and researchers) can talk about what they do in a way that is consistent. Therefore, although a number of components are found in only a few schools models, they warrant inclusion in the framework as in those schools they are considered essential to the schools' models and their identity as STEM schools. For example, Teacher Facilitation of the Engineering Design Process (EDP) was identified as essential in only 4 sample schools. However, at these four schools, this 
component is extremely important-course content and projects are heavily influenced by the incorporation of EDP. Consensus-building was the key focus in synthesis of the eight overarching elements, as we sought to create a framework that represented the major aspects of inclusive STEM high schools in general. One of the strengths of this framework is that even as it creates common language around what STEM schools have in common, it also allows us to see the variation that exists between STEM school models. As such, not all schools have essential components across all of the eight elements. For example, building and giving back to the External Community was not a key focus for several schools, and they do not have any critical components in this element. However, this element was identified as critical in many other schools, who do feel that a core part of their mission is to improve STEM education outside of their school, or to be an active, contributing member of their community.

Our desire to include all critical components identified by schools stems from our philosophy that there is no one correct model for an inclusive STEM high school. This is not a prescriptive framework; the goal is to facilitate outcomes research that can effectively account for these varied and complex contexts. This framework also serves as a tool for practitioners to build models based on goals for students.

In examining these critical components, however, we found one particularly noteworthy theme: a surprising lack of components that relate specifically to the science, technology, engineering, and math disciplines. This is not to say that the STEM schools involved in the study do not value the STEM subjects-the STEM disciplines are certainly present in these schools. Some STEM high schools focus heavily on STEM subjects by requiring a more rigorous course sequence in science and mathematics than what is required at the state level. Others incorporate a broader scope of STEM disciplinary courses, such as requiring all students to take an introductory engineering course. Still, others focus on STEM disciplines by integrating STEM disciplinary content across all courses, including English Language Arts and History. The importance of rigorous course content (STEM and non-STEM) is reflected in the Rigorous Learning Element, and future work in this study will more closely examine the extent to which STEM discipline-specific content is delivered in these schools. Still, it became clear during the model articulation process that when school leaders referred to "STEM," they were often not referring to disciplinary subjects. This finding suggests that STEM school leaders and stakeholders view a STEM school identity, and STEM in general, as rooted in the instructional practices (such as PBL and studentcentered learning) employed in, transferrable skills focused on, and positive and inclusive culture created at these schools.
The schools participating in this study seek to transform learning in all of the disciplines they teach; as such, the disciplinary STEM focus may be more implicit than other goals. When we asked school leaders about the missions and goals of their schools, they often described the importance of engaging students with real-world problems and developing them as critical thinkers and active citizens. These ideals, as well as many of the instructional approaches highlighted by the schools, far predate the STEM movement. Educational philosophers such as Dewey (1998), Piaget (Henson, 2003), Vygotsky (Moll, 1992), and Bruner (1960) have advocated for such approaches for over a century. These philosophers encouraged educators to view students as active participants in their own learning and considered citizenship and creative and inventive thinking to be important student outcomes. Although their strategies have been operationalized in the decades since in a variety of settings, the STEM school movement appears to have provided them with a new home on a national scale. For example, "student autonomy" is as a key focus in most schools and resides in three Elements: Career, Technology, and Life Skills; Problem-Based Learning; and Personalization of Learning. Similarly, "students making connections to the real world" was identified as a component in Problem-Based Learning and Rigorous Learning. "Collaboration," another central tenet, is a component in Career, Technology, and Life Skills and Problem-Based Learning. In this way, it appears that a modern definition of STEM employed by inclusive STEM high schools may be broader than the disciplines themselves, as may their goals for students.

While it would be difficult to argue against the importance of the strategies and goals that make up the eight elements, it is notable that the study participants generally did not focus on STEM disciplines when describing their models, particularly when we consider the strong national push for improved STEM discipline education. This context is crucial when examining student outcomes: if inclusive STEM high schools are not modeled to focus on STEM disciplines, should we expect different STEM discipline student outcomes from these schools compared to other non-STEM schools with similar instructional and cultural strategies? Current research on STEM schools often focuses on math and science achievement or on students' pursuit of STEM majors and careers (so far with mixed results, e.g., Gnagey \& Lavertu, 2015), but given the findings presented here, what STEM discipline outcomes can we reasonably expect to see from STEM schools? Defining and examining the quality of these schools and their critical components is beyond the scope of this paper, however, the findings here suggest that inclusive STEM high schools may have more in common with constructivist-based (non-STEM) school models than perhaps very discipline- 
focused selective STEM schools. Further research should examine all STEM school outcomes in the context of these varied models.

\section{Conclusions}

Given the growing emphasis on, and interest in, STEM schools, there is an urgent desire to understand their impacts on student outcomes. However, impact studies can only come after the field has a well-established way to answer the question: impact of what? This study takes a necessary first step. We have identified an empirically based STEM school model with eight conceptually sound elements, each of which is, in turn, comprised of empirically derived components.

The findings presented provide a portrait of inclusive STEM high schools across the USA. The eight elements and corresponding critical components describe the educational strategies shared by 20 inclusive STEM schools and provide a theoretical basis for measuring the implementation of these elements in inclusive STEM schools and considering the context for student outcome research. By studying the implementation of the elements and their components, we can begin to understand how and why they may or may not relate to critical student outcomes, such as positive self-efficacy for STEM disciplines, interest in STEM careers, college-going decisions, and graduating grade point average.

Practitioners may use this framework to consider how both elements and individual components may fit in with their own goals for students at a school or classroom level. This framework will also help policy-makers consider this same issue at a district or state level. Finally, this framework highlights the varied models and strategies used in inclusive STEM schools, providing important context for researchers considering the examination of implementation and student outcomes.

The strength of this framework is in its origin-that is, that it represents what inclusive STEM schools across the USA are actually setting out to do. This is of critical importance given that it seems even those in the same field may be working with varying ideas of what "STEM" means in today's education context. The eight elements framework bridges the often isolated plains of research and practice, providing common language and a platform for communication and coordinated work toward the mutual goal of improving education.

Funding

This study was funded by the National Science Foundation.

\section{Authors' contributions}

ML provided conceptual leadership, oversaw the data collection and analyses, and led the writing of this manuscript. EN contributed substantially to the conceptual development, analyses, and writing of this manuscript. HK and SH are additional core developers of the framework. JC, CB, and Al provided editorial feedback and review. SL created tables, figures, and provided editorial feedback. All authors read and approved the final manuscript.

Competing interests

The authors declare that they have no competing interests.

\section{Author details}

1Outlier Research \& Evaluation, UChicago STEM Education, University of

Chicago, 1427 E. 60th Street, Chicago, IL 60637, USA. ²Current address: Youth Guidance, 1N. LaSalle Suite 925, Chicago, IL 60602, USA.

Received: 2 September 2016 Accepted: 28 October 2016

Published online: 21 November 2016

\section{References}

Alper, J. (1993). The pipeline is leaking women all the way along. Science, 260(5106), 409-411.

Bill \& Melinda Gates Foundation. (2014). Early progress: Interim research on personalized learning. Retrieved from http://k12education.gatesfoundation. org/wp-content/uploads/2015/06/Early-Progress-on-Personalized-LearningFull-Report.pdf

Blackburn, B. R. (2008). Rigor is NOT a four-letter word. Larchmont: Eye on Education.

Blickenstaff, J. C. (2006). Women and science careers: leaky pipeline or gender filter? Gender and Education, 17(4), 369-386. doi:10.1080/09540250500145072.

Bond, G. R., Evans, L., Salyers, M., Williams, J., \& Hea-Won, K. (2000). Measurement of fidelity in psychiatric rehabilitation. Mental Health Services Research, 2, 75-87.

Brundiers, K., Wiek, A., \& Redman, C. L. (2010). Real-world learning opportunities in sustainability: From classroom into the real world. International Journal of Sustainability in Higher Education, 11(4), 308-324.

Bruner, J. S. (1960). The process of education. Cambridge: Harvard University Press.

Century, J., \& Cassata, A. (2014). Conceptual foundations for measuring the implementation of educational innovations. Treatment Integrity: A Foundation for Evidence-Based Practice in Applied Psychology, 81-108

Century, J., Cassata, A., Rudnick, M., \& Freeman, C. (2012). Measuring enactment of innovations and the factors that affect implementation and sustainability: Moving toward common language and shared conceptual understanding. The Journal of Behavioral Health \& Services Research, 39(4). doi:10.1007/s11414012-9287-x

Century, J., Rudnick, M., \& Freeman, C. (2010). A framework for measuring fidelity of implementation: A foundation for shared language and accumulation of knowledge. American Journal of Evaluation, 31(2), 199-218.

Committee on STEM Education National Science and Technology Council. (2013). Federal science, technology, engineering, and mathematics (STEM) education: 5year strategic plan. Retrieved from http://www.whitehouse.gov/sites/default/ files/microsites/ostp/stem_stratplan_2013.pdf

Council, N. R. (2011). Successful K-12 STEM Education: Identifying Effective Approaches in Science, Technology, Engineering, and Mathematics. Committee on Highly Successful Science Programs for K-12 Science Education, Board on Science Education and Board on Testing and Assessment, Division of Behavioral and Social Sciences Education. Washington, DC: The National Academies Press.

Council, N. R. (2013). Monitoring Progress Toward Successful STEM Education: A Nation Advancing? Committee on Evaluation Framework for Successful K-12 Education, Board on Science Education, Board on Testing and Assessment, Division of Behavioral and Social Sciences and Education. Washington, DC: The National Academies Press.

Damschroder, L., Aron, D., Keith, R., Kirsh, S., Alexander, J., \& Lowery, J. (2009). Fostering implementation of health services research findings into practice: A consolidated framework for advancing implementation science. Implementation Science, 4(50). doi:10.1186/1748-5908-4-50

Dewey, J. (1998). Experience and Education. West Lafayette: Kappa Delta PI.

Gnagey, J. \& Lavertu, S. (2015). The impact of inclusive STEM high schools on student achievement. AERA Open. doi:10.1177/2332858416650870

Good, C., Rattan, A., \& Dweck, C. S. (2012). Why do women opt out? Sense of belonging and women's representation in mathematics. Journal of personality and social psychology, 102(4), 700-717.

Gugiu, P. C., \& Rodriguez-Campos, L. (2007). Semi-structured interview protocol for constructing logic models. Evaluation and Program Planning, 30(4), 339-350.

Hall, G. E., \& Hord, S. M. (1987). Change in schools: Facilitating the process. Albany: State University of New York Press. 
Harrison, M. (2011). Supporting the T and the E in STEM: 2004-2010. Design and Technology Education: An International Journal, 16(1), 17-25.

Henson, K. T. (2003). Foundations for learner-centered education: A knowledge base. Education, 124(1), 5-16.

Kelley, T. (2010). Staking the claim for the "T" in STEM. Journal of Technology Studies, 36(1), 2-11.

Klobuchar, A. (2014). STEM education for the innovation economy. Retrieved from http://www.jec.senate.gov/public/?a=Files.Serve\&File_id=9bfced75-07a0466b-a94b-8ab399582995

Langdon, D., McKittrick, G., Beede, D., Khan, B., \& Doms, M. (2011). STEM: Good jobs now and for the future. Washington, DC: U.S. Department of Commerce. Retrieved from http://www.esa.doc.gov/sites/default/files/stemfinalyjuly14_1.pdf.

Leboy, P. (2008). Fixing the leaky pipeline: Why aren't there many women in the top spots in academia? Scientist, 22(1), 67-70.

Leithwood, K. A., \& Montgomery, D. J. (1980). Evaluating program implementation. Evaluation Review, 4, 193-214.

Means, B., Confrey, J., House, A., \& Bhanot, R. (2008). STEM high schools: Specialized science, technology, engineering, and mathematics secondary schools in the United States. Menlo Park: SRI International.

Merrill, C. (2009). The future of TE masters degrees: STEM. Paper presented at the meeting of the InternationalTechnology Education Association, Louisville, KY

Moll, L. (1992). Vygotsky and Education. Cambridge: Cambridge University Press.

Mowbray, C. T., Holter, M. C., Teague, G. B., \& Bybee, D. (2003). Fidelity criteria: Development, measurement, and validation. The American Journal of Evaluation, 24, 315-340.

National Academies (National Academy of Sciences, National Academy of Engineering, and Institute of Medicine). (2005). Rising above the gathering storm. Washington, DC: National Academies Press.

Peters-Burton, E. E., Lynch, S. J., Behrend, T. S., \& Means, B. B. (2014). Inclusive STEM high school design: 10 critical components. Theory Into Practice, 53(1), 67-71. doi:10.1080/00405841.2014.862125.

Platz, J. (2007). How do you turn STEM into STEAM? Add the Arts! Retrieved from http://www.oaae.net/en/resources/educator/stem-to-steam

President's Council of Advisors in Science and Technology (PCAST). (2010). Prepare and inspire: K-12 education in science, technology, engineering, and math (STEM) for America's future. Washington, DC: White House Office of Science and Technology Policy.

Riley, D., McCann, C., \& Woods, Y. (2013). Moving STEM education forward: National priorities and the National Science Foundation's DR K-12 program. Community for Advancing Discovery Research in Education. Retrieved from http://cadrek12.org/sites/default/files/Moving\%20STEM\%20Education\%20 Forward08-02-2013.pdf

Rockland, R., Bloom, D. S., Carpinelli, J., Burr-Alexander, L., Hirsch, L. S., \& Kimmel, H. (2010). Advancing the "E" in K-12 STEM education. Journal of Technology Studies, 36(1), 53-64.

Sabelli, N., \& Dede, C. (2001). Integrating educational research and practice: Reconceptualizing goals and policies: "How to make what works work for us?" Retrieved from http://www.forschungsnetzwerk.at/downloadpub/2001_ sabelli_policy.pdf

Savery, J. R. (2015). Overview of problem-based learning: Definitions and distinctions. Essential Readings in Problem-Based Learning: Exploring and Extending the Legacy of Howard S. Barrows, 5-15.

Smith, J. L., Lewis, K. L., Hawthorne, L., \& Hodges, S. D. (2013). When trying hard isn't natural women's belonging with and motivation for male-dominated stem fields as a function of effort expenditure concerns. Personality and Social Psychology Bulletin, 39(2), 131-143.

Strauss, A., \& Corbin, J. (1994). Grounded theory methodology. In N. K. Denzin \& Y. S. Lincoln (Eds.), Handbook of Qualitative Research (pp. 217-285). Thousand Oaks: SAGE Publications.

Subotnik, R. F., \& Tai, R. H. (2011). Study of the impact of selective SMT high schools: Reflections on learners gifted and motivated in science and mathematics. Washington, DC: Committee on Highly Successful STEM Schools or Programs for K-12 STEM Education.

Unfried, A., Faber, M., \& Wiebe, E. (2014). Gender and Student Attitudes toward Science, Technology, Engineering, and Mathematics. The Friday Institute for Educational Innovation at North Carolina State University

United States Department of Labor. (2007). The STEM workforce challenge: The role of the public workforce system in a national solution for a competitive Science, Technology, Engineering, and Mathematics (STEM) workforce. Washington, DC Author. Retrieved from http://digitalcommons.ilr.cornell.edu/key_workplace/637
Valla, J. M., \& Ceci, S. J. (2014). Breadth-based models of women's underrepresentation in STEM fields: An integrative commentary on Schmidt (2011) and Nye et al. (2012). Perspectives on Psychological Science, 9(2), 219-224.

Wang, M. C., Nojan, M., Strom, C. D., \& Walberg, H. J. (1984). The utility of degree of implementation measures in program implementation and evaluation research. Curriculum Inquiry, 14, 249-286.

Wells, B. H., Sanchez, H. A., \& Attridge, J. M. (2007). Modeling student interest in Science, Technology, Engineering and Mathematics. Meeting the growing demand for engineers and their educators 2010-2020. International Summit, IEEE 2007, 50, 1-17.

Wickware, P. (1997). Along the leaky pipeline. Nature, 390, 202-203.

Young, V. M., House, A., Wang, H., Singleton, C., \& Klopfenstein, K. (2011). Inclusive STEM schools: Early promise in Texas and unanswered questions. Paper presented at the National Research Council Workshop on Successful STEM Education in K-12 Schools. Washington, DC

\section{Submit your manuscript to a SpringerOpen ${ }^{\circ}$ journal and benefit from:}

- Convenient online submission

- Rigorous peer review

- Immediate publication on acceptance

- Open access: articles freely available online

- High visibility within the field

- Retaining the copyright to your article

Submit your next manuscript at $>$ springeropen.com 